\title{
Entretien
}

\section{Helga Nowotny: an itinerary between sociology of knowledge and public debate}

\section{Interview by Pieter Leroy}

\author{
Helga Nowotny ${ }^{1}$, Pieter Leroy ${ }^{2}$ \\ 1 Professor emeritus Social Studies of Science, ETH, Zurich; Vice-President of the European Research Council \\ 2 Professor of Political Sciences of the Environment, Nijmegen University, 6500 HK Nijmegen, The Netherlands
}

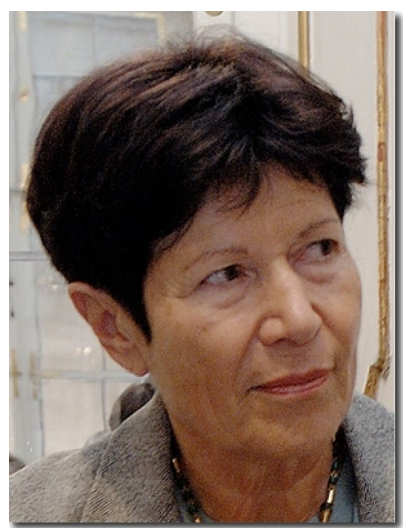

Helga Nowotny, professor emeritus nowadays, is a grand lady in the field that was originally labelled sociology of knowledge, and gradually became better known as STS: science and technology studies. As is clear from "Short biography" (Box 1) and "Research and publications" (Box 3), Helga Nowotny's œuvre is impressive and addresses a variety of issues. The interview deliberately focuses on themes that are close to the NSS agenda: knowledge production, the field of STS and the governance of research, starting, self-evidently, with a retrospect on Helga Nowotny's earlier work.
Pieter Leroy (NSS): How was it that you got a doctorate in law from Vienna University (1959) and then went to the USA, more precisely to Columbia University, to get a PhD (1969)?

Helga Nowotny: Following my doctorate in law I worked at the University of Vienna as an assistant professor in its Institute of Criminology. It was there that I became interested in sociology, but also in the sociology of science, without yet knowing that such a field existed. We did a lot of technical and scientific expertise at the Institute. I began to be interested in how the experts who testified in court influenced the sentence and how their expertise actually was produced and which were the biases that intruded. I realized that I had many questions and very few answers. Therefore, when I moved with my husband to New York and it became clear that I would not find a similar position there, I decided to study for a PhD in sociology.

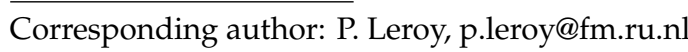

P.L.: Was there a particular professor at Columbia who got your attention?

Helga Nowotny: The day after I had decided that I wanted to obtain a PhD in sociology at Columbia, I went to see Paul F. Lazarsfeld, an Austrian emigrant scientist who had left Vienna before Hitler took over. I was very keen to learn empirical methods, but soon discovered that they were merely tools that have to be matched with the right kind of questions. It was questions I was interested in. Robert K. Merton was, of course, the other towering figure in the department. These two, plus a few others, gave me a wonderful and solid foundation to build upon further.

P.L.: In the late 1970s I first came across your earlier work: an analysis of the Austrian debates on the nuclear issue. How did you become involved in the nuclear debate? Was it a matter of political engagement, or did you just come across it, anticipating the nuclear issue to be exemplary? 


\section{Box 1. Short biography}

1959: Doctor juris, University of Vienna.

1960-1965: Assistant Professor at the Institute for Criminology, University of Vienna.

1969: PhD in Sociology (with Paul Lazarsfeld), Columbia University, New York.

1969-1972: Associate Professor, Department of Sociology, Institute for Advanced Studies, Vienna.

1980: Habilitation, Faculty of Sociology, University of Bielefeld. 1982: Habilitation, Grund- und Integrativwissenschaftliche Fakultät, University of Vienna.

1987 : Maitre d'études, École des hautes études en sciences sociales (EHESS), Paris.

1982-1987: Associate Professor, University of Vienna. 1987-1996: Professor of Social Studies of Science, Institute for Theory and Social Studies of Science, University of Vienna.

1990, 1992: Directeur d'études, EHESS, Paris.

1996-2002: Professor of Philosophy and Social Studies of Science, ETH Zurich (Swiss Federal Institute of Technology).

Current position:

Professor emeritus, Social Studies of Science, ETH Zurich. Vice-President of the European Research Council.

Personal homepage: http://www.helga-nowotny.eu/

Helga Nowotny: I already had an interest in scientific controversies and had published an article on these in 1973. This work, however, was purely theoretical. When a physicist friend in Vienna told me that the Austrian Ministry was about to launch the 'information campaign on nuclear energy' I immediately saw this as a unique opportunity for an empirical sociological study of a live controversy - and a big one, moreover. The person in charge in the Ministry was sufficiently broad-minded to see the potential relevance. I had access to all available data and to all the experts involved and I received a lot of background information. As to activism or lack of it, my guiding motto was inspired by Norbert Elias' notion of "involvement and detachment".

P.L.: In those days, I also was engaged in the nuclear debate. In retrospect, it seems that the nuclear issue, with all the technical, economic, moral and political arguments brought forward by different factions of pro- and antinuclear organisations was, among other things, a battle about modernity, its advantages and inconveniences, its way forward and its governance (if it ever would be governable). In this respect, the nuclear issue was a forerunner to a series of later scientific-technological controversies.

Helga Nowotny: Yes. This comes out even stronger with the benefit of hindsight. The nuclear controversy and the anti-nuclear movement were forerunners. The nuclear option was rightly perceived as one of the few, big choices that people could actually make: "in which kind of society do we want to live?" This had not happened before. The anti-nuclear movement, together with the environmental movement with all its internal heterogeneity, became the vanguard for the demands for public participation and deliberative democracy that have become mainstream today. Although nobody used the word 'governance of technology' then, this is what the struggle to a large extent was about.

P.L.: Could we extend this conclusion to many of the scientific-technological controversies you have analysed many of which are related to environmental and health issues? Do these controversies reveal the edges and boundaries of modernity, including modern science, with all its greatness and naivety?

Helga Nowotny: We have to understand the developments that followed in a broader context that influenced the organisational shape and content of subsequent scientific-technical controversies. As I see it, the hegemonic rule of the technocratic elites which had dominated up to the 1970s (in itself a sign of belated modernisation in many European countries after WW2), gradually came to an end. Social movements sprung up around scientifictechnical issues that crossed national boundaries and became rapidly transnational. The Golden Triangle of Science-State-Industry started to give way. Science itself was transformed internally through the widespread use of computers and through modelling, and its unintended effects on the organisation of scientific work. The State began to yield to market forces. Some political scientists even claim that today we no longer have nation-states, but only market-states. Industry lost the protection it had enjoyed thanks to its intimate relation to the State and to Science in the successive waves of denationalisation and privatisation. Modernity itself became transformed. In the current age of globalisation we live in a multitude of modernities.

P.L.: In one of your articles on the Austrian debate concerning the nuclear issue, after having observed that it was impossible to find the desired number of anti-nuclear experts, you conclude: "[... this is] a result of an historical legacy and of the existing institutional arrangements in which scientists work". This quote seems pivotal to me, in that it represents a typical feature of your analysis: moving from an analysis of this particular process on the referendum to the more organisational conclusion that the Austrian, by extension European, knowledge infrastructure was such that the envisaged equal access and representation of pro's and con's could not be assured.

Helga Nowotny: Yes, the social structure of experts was such that no parity could be achieved. This is perhaps not as surprising as it appears at first sight. While science needs criticism and thrives on it intellectually, the overall pressure is in the direction of seeking consensus and in arriving at the closure of controversies or arguments. The crucial question is one of timing: when to keep dissent 
open, and when to move towards a settlement? Even if it can only be a provisional one, there is a striving towards a dominant view - which may be overturned again. Therefore, what is needed are 'competent rebels' and a scientific community that welcomes them, since they are indispensable for the dynamics of science.

P.L.: These observations on the nuclear issue and your analyses of comparable controversies have led you to a 'sociology of organisations and institutions' approach, rather than to an epistemological one - which we will discuss below.

Helga Nowotny: I was always interested in both, organisations and institutions, but also epistemological questions. The crucial difference is that the former are easy to study empirically, while the latter are not. However, the question as to what extent and under which circumstances an institution becomes reflexive, continues to haunt me. Of course, one can find indicators for reflexivity or do before-and-after empirical studies. But what are the precise mechanisms that make it possible?

Coming back to the previous question: we not only need individuals who are competent rebels, but also institutions that act as competent rebels. This is much more difficult to achieve.

P.L.: But how is it that an epistemological pluralism could or should parallel a political one, as you state?

Helga Nowotny: This is one of the greatest challenges for the science and democracy relationship. I do not think that a pluralistic science is desirable in the sense that a political group should be allowed to impose its values on science and science produces results that fit those values. Thus, we should keep science distinct from politics and morals, even if such a strict separation will never be possible. Pluralism should be encouraged in both domains, without expecting that they will or should be mapped upon each other.

P.L.: Let us turn now to what is your best known work. In 1994 you co-authored, with Michael Gibbons and others, the seminal book The New Production of Knowledge (see Box 2) ${ }^{1}$. It became well known and well criticised, in particular for its focal concept 'Mode 2'. Before we turn to its content, how was it that - without ignoring the other co-authors - Michael Gibbons and you, both well experienced in chairing university's and other research institutes' boards, and yet with quite a different scientific background, came together?

Helga Nowotny: It is all the fault of a Swedish Research Council. Enlightened policy-makers there wanted to look ahead and get a better sense of the transformations the science system was undergoing. They asked Michael to set up an international group. We had complete freedom to proceed and to do what we wanted. Our mode

\footnotetext{
1 See also Barré, R., 2004. La science est morte, vive la science !, Natures Sciences Sociétés, 12, 1, 52-55.
}

of working became one where we met for two or three days in nice locations for intense discussion and back home started to write parts that were exchanged and rewritten by others. We decided early on a truly collective authorship, which is what it was.

P.L.: Is it fair to say that the 1994 book addresses the changing organisational context of knowledge production, i.e. the multiplication of producing actors involved and the increasing implication of knowledge users or consumers respectively, more than the changing character of knowledge itself, e.g. its way of coping with uncertainty and complexity?

Helga Nowotny: Not quite. The New Production of Knowledge book deals with the changing context, but also with changing structures inside the science system: the focus in Mode 2 on the initial joint problem-definition, on changing configurations of research team members who later return to their home discipline. We tried hard to capture the interdependencies between 'outside' (context), especially the shifting boundaries between state, market and culture and 'inside', how scientists responded, accommodated, but also anticipated and shaped the changing context.

P.L.: At first sight The New Production of Knowledge seems an analysis of current reality: the shifting contexts in which (scientific) 'knowledge' is produced, and the various implications thereof, in terms of scientific organisation (flat, temporary networks) and co-operation (interor transdisciplinary), in terms of quality management, in terms of science's societal relevance, etc. The book, however, was not a mere analysis, but implied a plea or a programme as well, while - and I quote an article of yours here -, it lacked an adequate social theory.

Would you, in retrospect, agree that while the book's message was pertinent, its presentation tended to generate misunderstandings? I refer to the Mode 1-Mode 2 dichotomy - archetypical in the social sciences, yet easy to criticise; to the somewhat artificial Mode 1 characterisation, whereas Mode 2 excelled in a wide variety of newly emerging practices; to the suggestion that we shift from 1 to 2, whereas Mode 1 and 2 may exist in juxtaposition as well, as comments and critics in scientific reviews stated.

Helga Nowotny: I came to the somewhat stoical conclusion that whatever care authors take to make themselves clearly understood, the moment the book is out, it will be interpreted by others, who all may have their own agenda in selecting and redefining the message they want to hear. It only proves that the authors had something to say that was of high policy relevance.

Thus, although we had clearly stated that we do not see our task to include a historical account, we were taken to task by the historians for ignoring history (which, they argued, proved us wrong in claiming that Mode 2 was something new, although they never had heard of predecessors). Although we had stated in several places 


\section{Box 2. On Mode 1 and Mode 2 knowledge}

In The New Production of Knowledge (1994, see "Research and publications", Box 3, for its full reference), Gibbons, Nowotny, Limoges and others launched the concept of Mode 2 science. The concept essentially refers to the new ways of knowledge production that differ from the features of traditional knowledge production.

In contrast to the latter, labelled Mode 1, Mode 2 is characterised by 5 distinctive characteristics:

1. Mode 2 knowledge is produced in a context of application. This implies, among other things, the implication of a variety of interests, from the beginning, hence including the very problem formulation.

2. Mode 2 knowledge is produced in an interdisciplinary, even transdisciplinary way. The concept 'transdisciplinarity' - widely discussed in German-speaking Europe - refers to the involvement of non-scientists, be it stakeholders and representatives from market agencies, from civil society, etc. Mode 2 knowledge production thus transgresses not only the boundaries of disciplines - as in multi- or interdisciplinarity -, but even the boundaries of the traditional science system - and its governance.

3. Mode 2 knowledge is characterised by the heterogeneity of its organisation. The groups and networks it is produced in are academic and non-academic, they are flat rather than hierarchically structured, they are international, interdisciplinary, temporary or even ephemeral and virtual. Modern communication technology facilitates and endorses these organisational features.

4. Mode 2 knowledge is socially accountable and reflexive: it reflects upon its own problem formulations, its processes and findings, and it is open to its different stakeholders who may ask 'what are you doing for us?'.

5. Mode 2 knowledge organises a system of quality control that is different from the traditional peer review. Next to scientists, non-science should also have a voice. And even though these questions are hard to answer, supplementary questions and criteria, on its added value, on its social robustness, etc., should be addressed.

In retrospect, the authors of the seminal book The New Production of Knowledge admit that the message has been misunderstood or wasn't sufficiently clear. Questions mainly asked what was novel about Mode 2, whether the Mode 2 concept resulted from empirical observations or was a rather normative concept, etc. See the interview for further comments and debate.

that we were writing an essay, or even a manifesto in parts, we were accused of having no theoretical underpinning. We were also accused of promoting the neo-liberal agenda, which in my view only meant blaming the messenger. Other colleagues indulged in petty criticisms that showed signs of envy and the 'not invented here' syndrome.

The message was taken up widely by policy-makers (whom we addressed in the first place) and enthusiastically greeted by those who felt they were on the margins of the academic hierarchy: people in design studies and architecture, transdisciplinary studies of all kinds, environmental studies, health studies, etc. They recognised themselves as the genuine practitioners of Mode 2. There were also citation studies that by and large confirmed the trend towards an increase in co-authored papers from different fields and institutions and other studies that focused on a specific dimension of Mode 2.

P.L.: One of the main notions of Mode 2 is the (need to) taking into account of the implications of knowledge production, which 'democratising science' seems to be the quintessence of. In The New Production of Knowledge - and in other works of yours - you mention the 'social robustness' of knowledge as a key feature. This robustness, however, is argued to be dependent on the specific context. This tends to imply, however, that it is hard to decide 'in robustness' on the very principles. Whether we talk about the nuclear issue, about GMOs or about similar issues of controversy, the 'robustness' issue comes up when real people in real life contexts face the actual consequences of a technology and its application. At that stage, though, one can no longer reject the very principle of the nuclear or other technologies.

Helga Nowotny: I do not think that robustness can be decided on principles alone. Robustness emerges in a process of variation and selection, and proceeds through shedding most of the available options. Socially robust knowledge must build on scientific robustness, but transcend it by including other dimensions and criteria that remain context-dependent. What can be integrated from the social sphere and how, depends on historical place and circumstances. One of the socially robust results of the many conflicts and 'dialogues' in the wake of the nuclear controversy was the extension of the concept of 'risk' itself. Initially, risk was narrowly defined as the amount of damage multiplied by frequency of occurrence. At the end of a series of interactive expert-lay conflicts and dialogues stands the recognition that risk is multidimensional and must include the social dimensions.

Experience shows that learning processes of such a kind are either triggered by major failures or catastrophes, or emerge from major conflicts and confrontation. Hopefully there is also learning from past experience, and from the crises and conflicts that precede it. There is also the tendency to professionalise, as seen in bioethics, with this curious split between (professionalised) ethics and (lay) morals.

To conclude: there is no one way as to how to organise public debates. Once it is recognised, however, that the outcome will be qualitatively improved, as well as the political risk reduced, if scientific knowledge and technical 
expertise are made socially more robust, we can work on finding the most efficient means of achieving it.

P.L.: In the 2001 Re-thinking Science book, the democratic argument is emphasised again, this time while re-introducing the classical 'agora'-principle. In the meantime, we witnessed a series of 'participatory approaches' to newly emerging technologies, be it high speed trains, UMTS, nanotechnology... Over the last two decades, these participatory approaches have spread all over Europe. Yet their actual impact seems minimal. Part of this is due to the - still - uneven access to knowledge from those involved - as was the case in the nuclear battle back in the 1970s. Hence, I dare insist: how is participation that really matters to be organised?

Helga Nowotny: I think we can see many changes, although not enough of them. In biomedicine, for example, patients have clearly gained in visibility and they have been empowered in a certain sense. In the environmental field, one of the big remaining problems is that the administrative-legal procedures have not been adequately adapted to take into account the results coming from the various deliberative fora and consultative procedures. I am afraid we will never have completely even access to information from all those involved, but I see improvements. Thus, while expectations of citizens have been raised, what is still lacking are adequate institutions to encourage them to experiment with their own choices and accompany them in the process of doing so. For this, we need public space, an agora.

P.L.: We might conclude these rather theoretical questions with a practical and a political one: you are well aware that the UK and France are on the brink of announcing a huge nuclear programme. Germany has some difficulty leaving its 'Atom-Ausstieg' behind, but it will follow in the end. Being a Belgian myself, I dare say that Belgium will have less difficulty and shame to do so. In brief, we seem to be at the eve of a 1973-revisited scenario: due to the increased oil prices, legitimised by the need to differentiate our energy supply, and - single new element - by the need to reduce $\mathrm{CO}_{2}$ emissions, Europe once again will opt for the nuclear. While this will be a transnational - not a European, in the sense of the EU - decision, there is no agora at all. At national level I even see further restrictions: the UK government refines its spatial planning legislation, thereby decreasing the opportunities for participation. In addition, it is very likely that the UK and France will opt for the existing sites to avoid location controversies.

The nuclear thus still seems to display the characteristics it had back in the seventies: a bastion of the classical government-industry nexus, and no Mode 2 at all.

Helga Nowotny: This is a very intriguing question; one that I have already posed to myself. But history does not repeat itself, however hard the nuclear industry may try. Do you know that the price of uranium has gone up 70-fold in the last ten years? Are you aware how long it takes to build new nuclear power stations in countries that do not have them already? Add to it the exponential increase of security and proliferation problems and the fact that terrorism - which was only hypothetical then has become real now. If there will be a renaissance, it will look very different.

My sober and realistic assessment is the following: only countries that already use the nuclear for military purposes will be able to afford to expand their nuclear civil programme. Only they can more or less guarantee that the necessary safeguards will be there, including the unresolved problem of how to handle/store nuclear waste (which will be recycled for military use). Therefore, I do not think that the option of the 1970s will re-occur: to go nuclear or not. Some countries will go more nuclear, others will not be able to afford it, even if they want to. In addition, there is now a much stronger awareness that alternative energies have to be taken seriously. Material scientists have begun work on entirely new materials which are needed if we want to tap the energy of the sun - the present technologies are far too small-scale. Other alternative energy sources have moved from the fringe closer into the realm of what may become politically feasible.

P.L.: Over the past decades, we have seen impressive efforts in the STS-domain: on knowledge production, on the role of knowledge in contemporary society, on the science-policy interface, etc. I have tried to sketch a family portrait, and your position amidst your colleagues. Your writings on a new mode of knowledge production coincide, for instance, with the writings by Silvio Functowicz and Jerry Ravetz. While their approach is mainly epistemological, their conclusions are largely similar to yours: the need for an open access to the steering of scientific developments, the quest for an extended system of quality management etc. Do you agree?

Helga Nowotny: The conclusions are similar indeed, but the ways of getting there differ. The difference I see is that epistemological problems were less in the forefront for me. My empirical streak always led me to pay attention to institutions, actual decision-making mechanisms and power relations. I agree that there are many similarities in the results of the diagnosis - which is fine with me. The different roads taken are an expression of epistemological pluralism, but also of different individual and collective biographies (and the problem choices they entail).

P.L.: Sheila Jasanoff has done a lot of work on the analysis of science-policy processes and, in particular, on the role of experts therein. Her analysis bears less on the institutional aspects of knowledge production, and more on the processing of expertise in specific settings. Do you agree?

Helga Nowotny: Sheila's work is much inspired by and oriented towards the role played in the US by law 
and the courts. Her work is also explicitly comparative, since she analyses in depth the comparative settings in which for example the regulation of biotechnologies occurs in otherwise similar, Western liberal democracies. Institutional contexts, self-evidently, do play a crucial role therein.

P.L.: Both of you argue that an experts' role is decisive exactly at the point when he/she crosses the borders of his/her discipline, and enters into the realm of 'expertise'. An expert seems to largely play a Panoramix-role: he magically prepares the magic potion without others being able to really get a finger on what he is doing, and yet it works... Is the role of the expert still an underscored issue in the field of STS?

Helga Nowotny: I like the magic potion analogy. This is the strength and weakness of any alternative medicine: it cannot be standardised and replicated. Expertise, in its content at least, cannot be standardised either, since it is too context-sensitive. What can and should be standardised are the procedures - but they do not produce the outcome; they only protect from undue influences. Every expertise is transgressive in the sense that an expert claims more than he/she can sustain given their professional competence. This is so, because the 'problem' is highly contextualised. By taking it out of its context, expertise becomes a series of abstract guidelines or precepts - and useless for the policy-maker who has to act often under time pressure and in a context, that constrains him/her in a very specific way.

P.L.: Does this mean that 'expertise' can only play its role when it enjoys some 'autonomy'? Even though this autonomy is largely fictitious, yet it is part of the experts' professional equipment.

Helga Nowotny: The issue of autonomy needs more differentiation. If by autonomy you mean an 'independent' position, then it is largely fictional, since all experts are employed by some institution. However, autonomy as a state of mind and an ethos is far from being fictional. I experienced a 'dilemma of expertise': if you are too close to the decision-makers in the way you think and identify with their objectives, you risk becoming useless, since the outcome will be too similar. If you are too distant or 'independent', you risk becoming irrelevant, since you do not identify enough.

P.L.: Thomas Gieryn has a different stance, when he analyses boundary work done by boundary workers, using boundary concepts. This seems a helpful concept to analyse the Janusian position of many research-andadvice institutions, advisory committees, etc.

Helga Nowotny: I highly respect Tom and his work. I have quoted him and used his work in my teaching. I find the boundary concept very useful when trying to explain to people why they see things in a different light and yet, despite obvious conflicts, can still communicate.
But I have found it of limited added value to my own work, maybe because it seems so obvious to me.

P.L.: Brian Wynne, Alan Irwin and other scholars have done a lot of work on lay knowledge, on citizen science... From the nuclear issue, from the debates on GMOs, dioxins, BSE and others, we know that, where the involvement of lay knowledge is significant, there is a risk of a popularisation of science that brings about invalid and unreliable 'science'. This, again, raises the question: how to combine the quality standards of 'normal' science (validity and reliability), with the quality standards that you and your colleagues put forward?

Helga Nowotny: Social robustness must build on reliable science, otherwise we move on quicksand. It is the extension of scientific insights, methods and expertise that matters, and science's willingness to be more open and inclusive. This extension and the criteria and mechanisms through which it occurs are highly selective themselves: what is taken up from lay experience or acknowledged to be a legitimate demand or constraint varies a lot - as is to be expected -, and so does its success or failure in contributing to making the actual technology or scientific development socially more robust.

P.L.: You label the main criteria for extended quality as 'robustness', whereas others use qualifications such as democratising science, mobilising sub-political science, citizen science, transdisciplinarity, sustainability science, empowerment etc. This enumeration suggests that the differences between these scholars are minimal, in that they use different labels for largely similar developments, issues and pleas. Is this a fair conclusion? Or does it overlook differences that you regard to be crucial in the recent debate?

Helga Nowotny: It testifies to the strength of STS as a research field if people arrive at similar results even if they start from different premises and use different approaches. I have never been able to join the widespread academic play of wanting to create differences and 'unique selling propositions' only for the sake of being different.

These many qualifications describe well a situation of emergence of robustness, whose form and structure is not yet completely visible. I have become convinced that robustness is one of the crucial design principles that can be found in natural systems, in engineering and in social systems. The stability of the system is crucially achieved through shedding, i.e. eliminating those structural principles which are found to be unnecessary or too volatile. Much of this proceeds by trial and error. The rest is history (i.e. path dependence or historical configurations with their own inertia). This may sound like a kind of neo-functionalism, but there is something to it.

P.L.: Your work discusses a series of developments in science. Among others: from largely closed and privileged government-industry-academia relationships to a multitude of agencies involved; from well-established 


\section{Box 3. Research and publications}

Helga Nowotny's research interests have moved from macrosociology and its methodology to social studies of science and technology (STS). Her work in the 1970s and 1980s includes topics such as scientific controversies and technological risks, including the nuclear debate, on coping with uncertainty, on self-organisation in science, on social time and on gender relations in science. Below we selected only a few titles that are of particular interest in relation to the interview:

1978: Information and opposition in Austria's nuclear energy policy [with H. Hirsch], Minerva , 15, 3-4, 314-334.

1980: The role of experts in developing public policy: The Austrian debate on nuclear power, Science, Technology and Human Values, 32, 10-18.

1985: Social science research in a changing policy context, in Nowotny, H., Lambiri-Dimaki, J. (Eds), The Difficult Dialogue between

Producers and Users of Social Science Research, Vienna, European Centre for Social Welfare Training and Research.

1987: Science for public policy: a new branch of science, in Brooks, H., Cooper, C. (Eds), Science for Public Policy, Oxford, Pergamon Press.

1993: Sociology as a discourse system: The impact of social movements upon sociological theorizing, Schweizerische Zeitschrift für Soziologie, 19, 3-7.

1993: Science meets the public: A new look at an old problem [with U. Felt], Public Understanding of Science, 2, 4, $285-290$.

1994: The New Production of Knowledge: The Dynamics of Science and Research in Contemporary Societies [with M. Gibbons, C. Limoges,

S. Schwartzman, P. Scott, M. Trow], London, SAGE.

2000: Transgressive Competence. The Narrative of Expertise, European Journal of Social Theory, 3, 1, 5-21.

2000: The production of knowledge beyond the academy and the market: A reply to Dominique Pestre, Science, Technology $\mathcal{E}$ Society, 5, 2, 183-194.

2001: Re-thinking Science: Knowledge and the Public in an Age of Uncertainty [with P. Scott and M. Gibbons), Cambridge, Polity Press. 2003: Democratising expertise and socially robust knowledge, Science and Public Policy, 30, 3, 151-156.

2003: Introduction: Mode 2 revisited: The new production of knowledge [with M. Gibbons and P. Scott], Minerva, 41, 3, 179-194.

2005: The Public Nature of Science under Assault: Politics, Markets, Science and the Law [with D. Pestre, E. Schmidt-Aßmann, H. Schulze-Fielitz, H.H. Trute], Heidelberg, New York, Springer.

2006: Real science is excellent science: How to interpret post-academic science, Mode 2 and the ERC, JCOM - Journal of Science Communication, 5, 4 (on line: http://jcom.sissa.it).

boundaries between science and society to an almost permanent blurring of these borders. One of the results is that, while responsibilities increased, due to increased risks, competencies and capacities to govern have been fragmented and scattered all over the place. Consequently the question arises as to who will do the necessary innovative research? Innovative in the sense of not pathdependent, highly valuated, high risk, and yet presumably essential for a sustainable future: on sustainable energy systems, on new mobility systems, to name but a few examples?

Helga Nowotny: This is precisely what we try to do in funding highly innovative basic ('frontier') research through the ERC ${ }^{2}$. Whether we will succeed in our ambitions remains to be seen, as it depends upon how much the panels are willing to actually fund high-risk projects. So it is really too early to tell. What is perhaps the most significant feature of the ERC in this context is that it is truly bottom-up.

P.L.: The ERC aims at strengthening the role of basic research, including in the social sciences, but I am not sure about its role regarding the governing and steering of this basic research into the aforementioned long-term questions.

Helga Nowotny: This is precisely the point. There is no steering in basic research. Of course, we operate with the various scientific communities and these operations

2 European Research Council (http://erc.europa.eu). take place in what I call the collective problem space. It is an epistemological as well as a social (and institutional) space. It yet acts as another, necessary, constraint.

P.L.: What do you mean by a 'collective problem space'?

Helga Nowotny: In a recent commentary in the SocioEconomic Review, I write on the importance of problem choice and the collective problem space: "Problems, while having a scientific lineage which is often more influential than disciplinary history is ready to admit, do not simply follow a linear tradition, nor is novelty privileged as such. Problems are not given, since Nature does not whisper into the ear of a scientist which problem to choose. Problem choice remains undervalued as a phenomenon and underresearched as practice, perhaps because it remains so firmly wedded to the belief in the autonomy of the scientific community and the high social value assigned to free scientific inquiry". Problem choices, if they are to have an impact, must become institutionalised, contextualised, embedded and nurtured in a collective problem space. It needs to be reconfigured from time to time. This is, if you want, the normative side of the collective problem space.

P.L.: One of the side-effects of the internationalisation in France one would tend to say, the Americanisation - of research is the application of performance indicators as a main instrument of its quality management. Quality systems do not only measure, they always have behavioural 
effects on those measured. Would you agree on the possible and actual perverse effects of these measurement systems, in that they risk reinforcing an old-fashioned Mode 1 science: forcing researchers to publish in disciplinary journals that are hardly accessible for average citizens. In contrast, researchers risk not to be rewarded for taking part in, to name but a few examples, debates on the nuclear, in participatory processes on UMTS, in supporting citizens to get access to scientific information etc.

Helga Nowotny: I fully agree on the many perverse effects that the current evaluation mania brings with it. In the UK the evaluation system will even be replaced by pure metrics systems: only indicators and figures; no more expert judgement. We all know that such systems bring about the apparently wanted behaviour, as well as cynicism and outright subversion. On the other hand, what are the roots for this drive towards hyper-evaluation? A major part are risk management strategies on the part of the administration, driven by the (real and invented) spectre of accountability, transparency, etc. - the colours in the flag of the new governance regimes! In the 1970s Michel Crozier wrote a classical book on how bureaucracy exploits uncertainty for its own ends. We have plenty of uncertainties now - and new sophisticated tools to exploit them. On the other hand I believe that researchers are too inventive and clever and politicians know that they risk killing the goose that lays the golden eggs if creativity and scientific curiosity are stifled too much. Therefore, subversive islands appear all of a sudden, researchers learn to organise themselves better, and there may even be cases where the evaluation process works reasonably well, as in the German Excellence Initiative, which achieved for the German university system what France still has to achieve. We are in a phase of transition, especially the continental universities. We have not reached the end of the story as yet.

P.L.: Finally, another dilemma emerges: how to combine the somewhat one-sided assessment standards that emphasise scientific performance in (English spoken) journals, with the quest for a societal relevant science including providing the counter-expertise that our society needs?

Helga Nowotny: This is part of the ongoing process of contextualisation of the science system. As with European universities, developments point in the direction of greater differentiation (or stratification, if you like). There will be an elite segment, an A league, where researchers are held to the highest international standards that will remain relatively narrowly focussed on excellence only. But there is plenty of space for other leagues - and even other sports - to emerge. What matters is that boundaries do not become closed, neither vertically (up- and downward mobility must be assured in accordance with criteria that are considered legitimate and hence remain open to revision), nor horizontally: there is more exchange going on between disciplines and between institutions than may be apparent to the observer. In other words, I see more Mode 2 actually occurring than what may be reflected in official figures. 